\section{SOI: 1.1 /TAS DOI: $10.15863 /$ TAS International Scientific Journal Theoretical \& Applied Science}

\author{
p-ISSN: 2308-4944 (print) e-ISSN: 2409-0085 (online) \\ Year: $2015 \quad$ Issue: $04 \quad$ Volume: 24
}

Published: $30.04 .2015 \quad$ http://T-Science.org
Ekaterina Andreevna Zaitseva

student,

Financial University under the Government of the Russian Federation (Kaluga Branch), Russia zaytsewa.katyuschka@yandex.ru

SECTION 21. Pedagogy. Psychology. Innovations in the field of education.

\title{
THE EDUCATION SYSTEM IN THE UNITED STATES: THE STRUCTURE AND FEATURES
}

Abstract: In the article are considered structure of an education system to the USA and essence of each education level, and also are revealed advantages and shortcomings of the studied educational system, the corresponding assumptions of their influence on positions of the USA in world ratings of quality of an average and higher education are provided. Results of the comparative analysis of state exams in the USA and the Russian Federation are presented.

Key words: Education system of the USA, primary education, middle education, SAT, the higher education, post-degree education, education.

Language: Russian

Citation: Zaitseva EA (2015) THE EDUCATION SYSTEM IN THE UNITED STATES: THE STRUCTURE AND FEATURES. ISJ Theoretical \& Applied Science 04 (24): 219-224.

Soi: http://s-o-i.org/1.1/TAS*04(24)39 Doi: crossef http://dx.doi.org/10.15863/TAS.2015.04.24.39

\section{СИСТЕМА ОБРАЗОВАНИЯ В США: СТРУКТУРА И ОСОБЕННОСТИ}

Аннотация: В статье рассмотрены структура системы образования в США и сущность каждого уровня образования, а также выявлены преимущества и недостатки исследуемой образовательной системы, приведены соответствующие предположения об их влиянии на позиции США в мировых рейтингах качества среднего и высшего профессионального образования. Представлены результаты сравнительного анализа государственных экзаменов в США и Российской Федерации.

Ключевые слова: Система образования в США, начальное образование, среднее образование, SAT, высшее образование, постдипломное образование, образование.

В каждой стране существует свой менталитет, свои особенности. Они проявляются как в обычаях и традициях, так и в политике государства. Не обходят стороной данные различия и систему образования. Вследствие этого, одни государства в международных рейтингах по качеству образования занимают лидирующие позиции, а другие - располагаются на последних местах. Вместе с тем, работники, обучавшиеся в одной стране, бывают более востребованы, чем работники с тем же уровнем образования, но получившие его в другом государстве.

Эти и другие причины, вызванные различиями в системах образования, стали мотивом для проведения данного исследования.
Так как США занимают не последние позиции в рейтингах образования, изучение особенностей его образовательной системы вызывает огромный интерес. В ходе исследования необходимо получить ответы на следующие вопросы:

- Какие существуют особенности в американском образовании?

- Какие позиции в мировых рейтингах образования занимает данное государство?

Для того, чтобы ответить на поставленные вопросы, необходимо сначала изучить структуру системы образования в США. Она схематично представлена на рисунке 1, составленном на основании данных Education Index [8] 


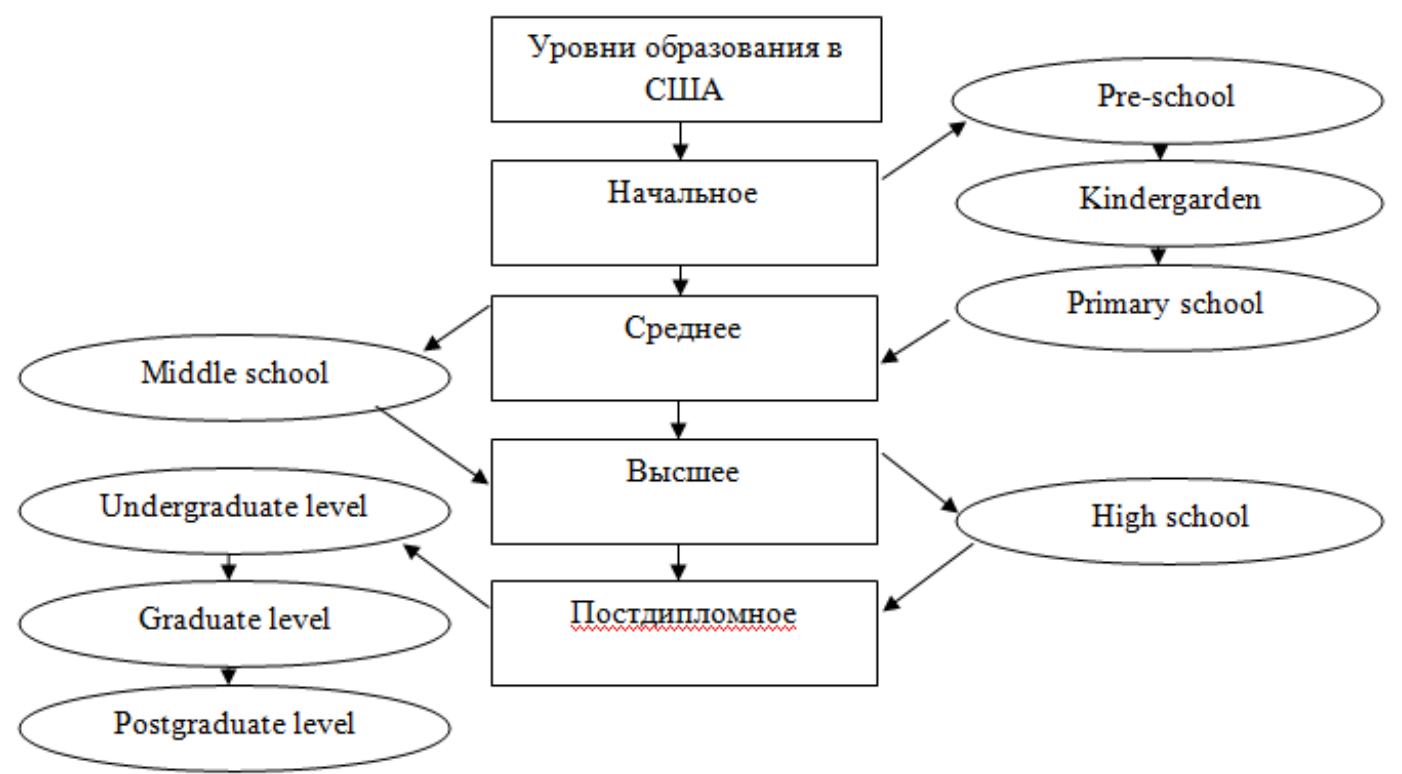

Рисунок 1 - Уровни системы образования в США.

Начальное образование начинается с дошкольной подготовки. Она включает в себя 2 уровня: «pre-school» и «kindergarden». «Preschool» - это самый первый уровень начального образования, на котором обучаются дети с 2 до 5 лет. С 5-6 лет детей отдают на 1 год обучения в «kindergarden», или детский сад, где они получают дальнейшее дошкольное образование [8].

В школу дети поступают в возрасте $6-7$ лет, в нулевой класс начальной школы, «primary school», где они обучаются 5 лет, арифметике, чтению и письму. На данном уровне естественные и общественные науки вообще почти не преподаются.

Далее следует средняя школа, «middle school». Она начинается с 5-6 класса и заканчивается 8 классом. В средней школе математику, английский язык, естественные и социальные науки, а также физкультуру изучают в обязательном порядке. Кроме того, одну или две дисциплины ученики вправе выбрать самостоятельно. По данным журнала «The Global Competitiveness Report» США в 2012-2014 гг. занимает достаточно низкие позиции в рейтинге стран по качеству среднего образования (табл. 1).

Таблица 1

Качество среднего образования в США, место в рейтинге

\begin{tabular}{|c|c|c|c|}
\hline Год & 2012 & 2013 & 2014 \\
\hline Позиция в рейтинге & 47 & 49 & 59 \\
\hline
\end{tabular}

Источник: Составлено автором на основании данных «The Global Competitiveness Report» 3 2012-2014 годbl [1], [2], [3].

Анализируя таблицу 1, можно заметить, что в США в 2012-2014 гг. наблюдается тенденция падения качества среднего образования. В целом, за данный период страна опустилась на 12 позиций, до 59 места. Причины ухудшения среднего образования можно увидеть не только во внешней среде, но и в самой образовательной системе США.

Так, одной из причин, по мнению Димиева, преподавателя из США, является само отношение американцев к образованию. Их идеология состоит в том, что в школу нужно ходить не для получения знаний, а для собственного удовольствия. Поэтому и изучаемые предметы носят игровой характер. Кроме того, на качество образования также оказывает влияние отсутствие конкретной методики преподавания точных наук, таких как математика, химия, физика и др. Учебные планы по данным предметам разрабатываются каждым учителем самостоятельно без какой-либо подоплеки в виде рекомендаций или обязательных стандартов [16].

Существующая в США идеология сильно препятствует улучшению качества американского образования, так как вследствие ее воздействия в 
Impact Factor ISRA (India) $\quad=\mathbf{1 . 3 4 4}$

Impact Factor ISI (Dubai, UAE) $=\mathbf{0 . 8 2 9}$

based on International Citation Report (ICR)

Impact Factor GIF (Australia) $\quad \mathbf{0} \mathbf{0 . 3 5 6}$
Impact Factor JIF $\quad=\mathbf{1 . 5 0 0}$

Impact Factor SIS (USA) $\quad=\mathbf{0 . 9 1 2}$

Impact Factor РИНЦ (Russia) $=\mathbf{0 . 1 7 9}$

Impact Factor ESJI $(\mathrm{KZ}) \quad=\mathbf{1 . 0 4 2}$
США потерялся истинный смысл и предназначение школы. Кроме того, отсутствие единой методики обучения точным наукам также не является сильной стороной системы образования, ведь в этом случае шансы на раскрытие потенциала и таланта к техническим наукам учащихся «тают» прямо на глазах.

Старшая школа, «high school», включает в себя с 9 по 12 классы образования, то есть 4 года, и предполагает самостоятельный выбор дисциплин, изучаемых подростками, исходя из широкого спектра обязательных предметов.

Еще одним минусом в образовательной системе США является отсутствие единых федеральных стандартов по учебным программам. У каждого штата существуют свои стандарты, что приводит к разному уровню знаний у выпускников. Для решения этой проблемы были разработаны итоговые экзаменационные тесты SAT (Scholastic Aptitude Test) и ACT (American College Testing), применяемые в разных штатах. Они немного различаются по своей структуре, но в целом дают примерно одинаковую оценку знаний выпускников [15].

Традиционно в США применяется SAT. Данный тест имеет 2 уровня: SAT I (Reasoning Test) и SAT II (Subject Test). Чаще всего университеты для поступления требуют только результаты теста SAT I, но наиболее престижные высшие учебные заведения устанавливают в качестве требования наличие результатов SAT II. Различия тестов SAT I и SAT II представлены в таблице 2.

Различия в тестах SAT I и SAT II.

Таблица 2

\begin{tabular}{|c|c|c|}
\hline Отличительный признак & SAT I & SAT II \\
\hline Содержание & $\begin{array}{c}\text { Общий тест на логическое } \\
\text { мышление, математические и } \\
\text { аналитические способности }\end{array}$ & $\begin{array}{c}\text { Tест по конкретным предметам, } \\
\text { которые изучал выпускник. }\end{array}$ \\
\hline Проверяемые области & $\begin{array}{c}\text { Критическое чтение, письмо, } \\
\text { математика }\end{array}$ & $\begin{array}{c}\text { Английский язык, история, } \\
\text { естественные науки, иностранные } \\
\text { языки }\end{array}$ \\
\hline
\end{tabular}

Источник: составлено автором на основании данных [10].

Проводя аналогию с общепринятой формой единого государственного экзамена в Российской Федерации, можно выделить сходства и различия, которые схематично приведены в таблице 3.

\section{Сходства и различия SAT и ЕГЭ.}

Таблица 3

\begin{tabular}{|c|c|c|}
\hline & SAT & ЕГЭ \\
\hline Сходства & $\begin{array}{ll}- & \text { Является вступительным экзаменом в } \\
\text { - } & \text { Является общеобязательным } \\
\text { - } & \text { В обязательном порядке проверяется } \\
& \text { анализировать прочитанное } \\
\text { - } & \text { Проводится в старшей школе } \\
\end{array}$ & основ математики, письма и умение \\
\hline \multirow[t]{2}{*}{ Различия } & $\begin{array}{c}\text { SAT I - проверяет знания по предметам в } \\
\text { комплексе } \\
\text { SAT II - по отдельным предметам }\end{array}$ & $\begin{array}{c}\text { Проводится только по отдельным } \\
\text { предметам }\end{array}$ \\
\hline & Проводится на английском языке & Проводится на русском языке \\
\hline
\end{tabular}




\begin{tabular}{|c|c|c|}
\hline & $\begin{array}{c}\text { (исключение составляют иностранные } \\
\text { дисциплины, экзамен по которым } \\
\text { проводится на сдаваемом языке) }\end{array}$ & $\begin{array}{c}\text { (исключение составляют иностранные } \\
\text { дисциплины, экзамен по которым } \\
\text { проводится на сдаваемом языке) }\end{array}$ \\
\cline { 2 - 3 } & $\begin{array}{c}\text { SAT II можно сдавать с 9-го класса после } \\
\text { окончания какого-либо предмета. Сдача } \\
\text { данного экзамена предполагается до 12 } \\
\text { класса обучения в школе. }\end{array}$ & $\begin{array}{c}\text { Можно сдавать досрочно по окончании } \\
\text { педмета, но только в выпускном классе. } \\
\text { Также можно сдавать спустя несколько } \\
\text { лет после окончания школы. }\end{array}$ \\
\cline { 2 - 3 } & Стоит около 30-40 долларов & Проводится бесплатно \\
\hline
\end{tabular}

Источник: Составлено автором на основании данных [5, с. 7], [15].

Анализируя имеющиеся данные, можно заметить существенные различия между SAT и ЕГЭ. Однако, вместе с различиями прослеживаются также и сходства, которые являются результатом глобализации и стандартизации образования.

По окончании старшей школы, выпускники получают диплом «High School Graduation Diploma», который учитывается при поступлении во всех университетах США и Канады.

Необходимо также отметить, что существует дополнительный 13 класс - Advanced Placement Programme. Данный класс предусматривает более глубокое изучение дисциплин, по которым планируется специализация в университете. Выпускники 13 класса зачисляются в университет сразу на 2-й курс [9].

Отличительной

особенностью образовательной системы США является то, что там нет организаций, аналогичных Министерству образования Российской Федерации, проводящего аккредитацию учебных заведений и утверждающих учебную программу. Все образовательные учреждения США являются независимыми в вопросах набора абитуриентов и методике образования.

Данная черта системы образования США является ее значительным минусом, так как контроль за процессом образования со стороны государства не только направляет его в нужное русло, но и обеспечивает достойный уровень образования по всей стране, в то время, как установление полной автономии образовательных учреждений приводит к существенному варьированию качества образования и уровня знаний даже в пределах одного штата.

Наконец, постдипломное образование представляет собой обучение в колледже или же университете. Первым и базовым уровнем высшего образования является «undergraduate level», то есть бакалавриат. Он состоит из двух типов: академического и профессионального. Академический бакалавриат также подразделяется на бакалавриат точных наук и бакалавриат гуманитарных наук. Профессиональный бакалавриат готовит работников сферы бизнеса [14].

Первые 2 года студент обучается общим или фундаментальным наукам и дисциплинам по выбору. На третьем курсе студент бакалавриата выбирает область, в которой он бы хотел специализироваться.

Еще одна уникальная черта системы высшего образования в США проявляется в том, что студент в процессе обучения вправе изменить направление в образовании и выбрать другую специализацию[11].

Вторым уровнем высшего образования, или постдипломным образованием, является магистратура или «graduate level». На данном уровне в США предлагаются 2 степени: магистр и доктор, для получения которых необходимо выполнить как исследовательскую работу, так и обязательную учебную программу. Данный уровень образования предполагает более глубокое изучение специализированных дисциплин.

Магистратура также подразделяется на академическую и профессиональную. Академическая магистратура включает в себя магистратуру гуманитарных наук и магистратуру точных наук. Для получения магистерской степени необходимо наличие степени бакалавра и год - два очного обучения с полной академической нагрузкой [13].

Профессиональная магистратура рассчитана на подготовку студента к конкретной профессии в бизнес - среде.

Степень доктора в американской системе образования является самой высокой научной степенью, присваивающейся после трехлетнего обучения и защиты докторской диссертации. Данная степень необходима для будущих ученых и исследователей, а также предназначена для преподавателей колледжей и университетов. В академической области чаще всего присваивается степень «Доктора философии», в 
профессиональной сфере - «Доктора педагогики», «Доктора управления бизнесом» и т. д. [13].

Необходимо отметить, что в Российской Федерации, несмотря на ее присоединение к Болонской системе, существуют свои ученые степени, такие как:

- $\quad$ Кандидат наук;
Считающиеся в США учеными степенями «бакалавр» и «магистр» в России представляют лишь квалификацию выпускников высшего учебного заведения.

Согласно данным международной сети университетов Universitas 21 США в 2012-2014 гг. по качеству высшего образования в рейтинге стран занимает позиции, представленные в таблице 4.

Таблица 4

Качество высшего образования в США, место в рейтинге.

\begin{tabular}{|c|c|c|c|}
\hline Год & 2012 & 2013 & 2014 \\
\hline Позиция в рейтинге & 1 & 1 & 1 \\
\hline
\end{tabular}

Источник: составлено автором на основании данньх Universitas 21[12].

Анализ таблицы 4 показывает, что США в 2012-2014 гг. сохраняет свои лидирующие позиции, занимая 3 года подряд первое место в рейтинге.

Таким образом, по итогам проведенного исследования следует сделать вывод, что, несмотря на происходящие в мире процессы интеграции и унификации, государства все еще имеют свои особенности и характерные черты в различных областях деятельности. Так, система образования в США успешно функционирует, позволяя добиваться высоких показателей и готовить высококвалифицированных специалистов. Однако, отсутствие единых образовательных стандартов, искаженный смысл процесса обучения в школе и предоставление широкой автономии образовательным учреждениям в вопросах набора абитуриентов и методике образования препятствует улучшению качества среднего образования и достижению более высоких результатов.

Научное исследование выполнено под руководством Петрушиной О.М., к.э.н., доцента кафедрь «Экономика» Калужского филиала ФГОБУ ВО «Финансовый университет при Правительстве Российской Федераичии».

\section{References:}

1. Schwab, Klaus (2013) United States. The Global Competitiveness Report. - 2012-2013. $440 \mathrm{p}$.

2. Schwab, Klaus (2014) United States .The Global Competitiveness Report. - 2013 - 2014. $-460 \mathrm{p}$.

3. Schwab, Klaus (2015) United States. The Global Competitiveness Report. - 2014 - 2015. - 456 p.

4. Balynin IV (2014) Financial support of education in the Russian Federation in 20082020. Audit and financial analysis. 2014. № 6. pp. 271-276.

5. Morozov M (2013) Profile education in general education as a factor in the US increase the effectiveness of vocational education. State testing of learning outcomes. Professional education in Russia and abroad. - 2013. № 1 (9) - pp. 6 - 8.

6. Balynin IV (2013) Education as a priority expenditure budget system of the Russian Federation. Man in the twenty-first century Proceedings of the VIII International scientificpractical conference of teachers and students. 2013. pp. 75-76.

7. Balynin IV (2014) Financial provision of social services at the federal and regional levels: plans for the years 2014-2016. Obl k, ekonomika, management: naukovi notatki Mizhnarodny 
Impact Factor ISRA (India) $\quad=\mathbf{1 . 3 4 4}$

Impact Factor ISI (Dubai, UAE) $=\mathbf{0 . 8 2 9}$

based on International Citation Report (ICR)

Impact Factor GIF (Australia) $\quad \mathbf{0} \mathbf{0 . 3 5 6}$
Impact Factor JIF $\quad=\mathbf{1 . 5 0 0}$

Impact Factor SIS (USA) $\quad=\mathbf{0 . 9 1 2}$

Impact Factor РИНЦ (Russia) $=\mathbf{0 . 1 7 9}$

Impact Factor ESJI (KZ) $\quad=\mathbf{1 . 0 4 2}$

13. (2015) American Consulting Center. Available: http://educationusarussia.org/ (Accessed: 21.04.2015).

14. (2013) Vahitov R. Bologna process in Russia . Domestic notes. - 2013. № 4 (55). Available: http://www.strana-oz.ru/ (Accessed: 21.04.2015).

15. Kravchenko A (2015) American SAT test and ACT: analogue exam in Russia? Available: http://inyaz-school.ru/amerikanskie-testy-sat-iact-analog-ege-v-rossii/ (Accessed: 21.04.2015).

16. Petrova M (2015) Schooling in the United States: the pros and cons. Political Education. Available:

http://www.lawinrussia.ru/node/262080 (Accessed: 21.04.2015). 